\title{
Editorial: Stupidity
}

\author{
PAUL RAE
}

As anyone who has dealt with bureaucrats or authoritarian regimes knows, sometimes it pays to act a little dumb. Glazing over good-naturedly in the face of a petty or corrupt demand can occasionally bring to light the inanity or cruelty of the situation in such a way as to prompt a momentary softening, be it through pity, impatience or even embarrassment. The stakes in such situations can be high: in the domain of the international with which this this journal is preoccupied, it might concern free passage on the one hand, or the right to remain, unhindered, on the other. More often the circumstances are banal, though not, for all that, without complexity. They point not only to the importance of stupidity as an enabling feature of life in complex and diverse modern societies, but also to the myriad forms it can take, from strategic ignorance, through the stupefaction necessary to manage the teeming stimuli of urban environments, to willing, if circumspect, participation in whichever confederacy of dunces makes up our place of employment, the organizations with which we affiliate, or the communities in which we participate.

Such remarks hardly represent a propitious opening to this issue of Theatre Research International, and to confess that stupidity has been on my mind as I have edited it does not promise to improve matters. However, as should already be clear, to treat stupidity as an offensive epithet targeted at individuals is to fail to recognize its structural, and sometimes even productive, dimensions. Both the exigencies and aims of editing entail a degree of stupidity, most apparent in the requests for clarification and further information that pepper the comments of drafts being returned to authors. 'I don't understand'; 'What does this mean?'; 'Who is this?'; 'When did this happen?': such is the stock-in-trade of the line editor, all the more so, perhaps, in an international journal where one of the main goals is to ensure that a general readership can derive new insights into ideas and practices in which they are interested, from cultural contexts with which they may be unfamiliar. I never fail to be amazed by the patience and good grace with which authors respond to such impertinent questions. I know from my own experience as an author how exasperating it can be when an editor appears to miss the point, or to claim ignorance of a historical or cultural detail I thought self-evident. But having had the good fortune to work with some excellent editors, I also know that beneath the spluttering indignation at each apparently wilful misconstrual of my lovingly tended prose lies the recognition that they are there to compensate for the necessary stupidities of writing itself. As Avital Ronell notes, with questionable reassurance, 'stupidity sets the mood that afflicts anyone who presumes to write'. ${ }^{1}$ And while it is certainly not for me to accuse any other author - least of all those doughty souls whose detailed, impassioned and insightful work appears in the present issue - of any particular species of ignorance, I have come to realize that certain patterns of oversight or obliviousness would appear to 
be almost inherent to academic writing: necessary conditions for getting a draft off the desktop and into an editor's inbox. Information and exposition are obvious examples here. There is always something of a misalignment between the writer one needs to be to get anything down, and the reader one ultimately writes for. Indeed, in order to say anything convincing about something, one must cultivate an insensibility to almost everything else: it is little wonder that writers so routinely omit the obvious but necessary details a reader needs to orient themselves to the subject matter, so deeply must they immerse themselves in it. At the other end of the spectrum of writerly oversight is structure - so often the proverbial wood authors lose sight of as they attend to the trees and branches of paragraph and sentence. In my own experience as both writer and editor, I have been struck by how important some judicious but substantive rearrangement of paragraphs can be in drawing out a logic that must have been at work in the author's critical imagination, but somehow fell afoul of whatever else it took to put one word after the next sufficiently cohesively as to get from the beginning to the end of a submissionready draft.

I dwell here on the multiple - and, ideally, complementary - stupidities of editing and writing for a couple of reasons. The first seems far removed from the practices I have just outlined: the desire to make sense of recent developments in the public discourse and political landscape of the UK and the US. There are many reasons for the triumph of the campaign for the UK to leave the European Union, and for Donald Trump in the US presidential elections. But it is inescapable that both came in part on the back of a coarsening of public discourse, where complex problems, especially those concerning cultural difference and the international domain, were not only radically simplified, but actively disdained. Whatever the subsequent outcomes, it seems we have entered a period - one with global reverberations far beyond the Anglo-American context - where stupidity, to paraphrase Gilles Deleuze, 'structures thought' to a significant degree. ${ }^{2}$ Moreover, it does so in strikingly performative ways that can only implicate theatre scholars: vindicated in their prior claims to performative efficacy on the one hand, and queasy at the uses to which it has been put on the other. '[A] tyrant institutionalises stupidity', writes Deleuze, 'but he is the first servant of his own system and the first to be installed within it'. ${ }^{3}$ It is tempting to derive an appalled satisfaction from watching President Trump flail in an imbroglio of his own making. But the more proper response must surely be concern at the extent of the system thereby institutionalized. It has pulled in so many elements of politics, performance and protest, and configured them in such a way as to compel participation regardless of personal views or investments, threatening to stupefy all it touches. Stupidity, continues Deleuze, 'is the faculty for false problems; it is evidence of an inability to constitute, comprehend or determine a problem as such'. And it does seem that, beyond the immediate challenges of resistance being launched by those most directly and materially impacted by these developments, lies the need to tear our gaze from the news cycle and the social media feed and to redouble our efforts to identify and articulate the problems abroad in the world around us as a first step to arriving at solutions.

Such global themes may seem a far cry from the diverse preoccupations of a handful of writers featured in a specialist theatre studies journal. However - and this is my second 
reason for dwelling, above, on editing and writing - it should be apparent by now that cultivating and communicating expertise are entirely apt responses to the developments just discussed, all the more so when the pace and intensity of new developments seem to call forth ever more ill-considered, abusively phrased and polarizing opinions. No article is perfect in itself. Ideally, it opens onto productive debate and the informed development of its ideas. But the above-mentioned dance of complementary stupidities involved in writing and editing are a necessary part of this process. With luck, they exhaust each other, leaving work of greater intelligence and integrity behind. In the case of theatre studies, the specific obligation to do this derives from the intelligence and integrity we invariably find at work in the production, presentation and reception of performance. Each is a process that must contend with its own genre of stupidity, in order to explore, if not settle, something insensible in the larger societies of which such enterprises are a part.

There is perhaps no more celebrated theatrical treatment of the encroachments and temptations of the insensible than Samuel Beckett's Waiting for Godot (1953), which Wei Feng considers in the context of Chinese Opera in 'Performing Comic Failure in Waiting for Godot with Jingju Actors'. Feng focuses on the process of adaptation undertaken by the Taiwanese Contemporary Legend Theatre, directed by Wu Hsing-kuo. The company is renowned for fusing jingju (Beijing opera) techniques with plays from the Western canon, but, as Feng explains, Beckett's play posed a number of specific formal challenges concerning the performance of the comic failures that underpin the characters' inability to gain metaphysical purchase on the world around them. Although Wu decided to build his adaptation around the chou, or clowning, role type in jingju, this did not substitute for Godot's associations with slapstick and vaudeville in any straightforward way: apart from anything else, notes Feng, it is harder to perform failure in chou without being seen to have failed in one's performance by a jingju audience. Feng carefully traces the theatrical solutions Wu and his actors found to this intriguing intercultural problem, and goes on to explore what those solutions in turn highlighted about aspects of Beckett's original play.

In a very different cultural context, Gay Morris also traces how creative solutions have been found to an intercultural theatre problem, though in this case the situation concerns not a play and a performance genre from opposite sides of the world, but rather from different parts of the same conurbation. 'Dinosaurs Become Birds: Changing Cultural Values in Cape Town Theatre' begins with an evocative characterization of township theatre, created far from the wealthy metropolitan centre of the multi-ethnic South African city. Preoccupied by questions of access, recognition and, ultimately, a living wage for the creators of such work, Morris notes a range of initiatives that have sought to draw town and township theatre cultures together, identifying the Zabalaza Festival at the University of Cape Town's Baxter Theatre as amongst the most successful. While the core of the annual festival consists of the presentation of a relatively small number of carefully selected performances at the venue, Morris patiently unfolds the extensive developmental work that the organizers undertake within the townships, as well as the details of organization, funding, audience development and artist professionalization that, in Morris's view, have rendered the Baxter much 
more incrementally and substantively successful in its mission than better-funded state institutions with a related remit.

Seokhun Choi's 'The Marionette: Intermedial Presence and B-Boy Culture in South Korea' draws together Feng's focus on a specific performance practice and Morris's attention to the contexts of theatrical production to make sense of one of the most popular South Korean b-boy shows: a distinctive genre integrating virtuosic breakdancing with a full-length narrative and, in this case, pre-recorded video. A massive popular hit, The Marionette is an especially rich site for an enquiry into the play of media and live performance since, as the title suggests and Choi highlights, the show turns on the relationship between a group of puppets who are played by humans, and various puppet masters, including media representations. For spectators, argues Choi, the intermedial dynamics of The Marionette are marked by several factors that sit in productive tension with each other: the media history of b-boying in South Korea, which means it has always been inhabited by its media representations and modes of transmission; an even distribution of spectatorial attention across live and mediated representations within the work; and yet a small but persistent 'friction' within the work, when the dancing fails seamlessly to align, as it must inevitably do, with the pre-recorded material.

By contrast, it is the absence of virtuosity and the jerry-built approach to mediatization that is of interest to Clare Finburgh in "Violence without Violence": Spectacle, War and Lola Arias's MINEFIELD (CAMPO MINADO)'. Finburgh's is the first of two pieces in this issue that focus on the 2016 show, performed by six former soldiers from the UK and Arias's native Argentina who, in 1982, had fought over ten weeks in what is known in English as the Falklands War, and in Spanish as La Guerra de las Malvinas. For a variety of reasons, including patriotism, belligerence and propaganda, the advent of war invariably increases the quantum of social stupidity, and Finburgh opens her article by considering the role of spectacle in the contemporary prosecution of war, before going on to elaborate on the ways MINEFIELD can be seen as a theatrical response. Finburgh draws on the ideas of the philosopher Jean-Luc Nancy, who argues that, while the formal strictures of art must represent a violent imposition upon the inchoate matter of the world, it is capable of doing so independently of the ideological structures that would otherwise instrumentalize that violence. Finburgh goes on to elaborate the ways in which Arias's distinctive form of documentary theatre, devised with her collaborators, used a variety of aesthetic strategies to explore the lived experience and the legacies of the conflict.

The second essay to reflect on what it now becomes appropriate to call CAMPO MINADO is by Cecilia Sosa, who saw the performance both in London and in Buenos Aires and was struck by the differences in the tone of its reception in the two countries. The result is 'CAMPO MINADO/MINEFIELD: War, Affect and Vulnerability - a Spectacle of Intimate Power'. Given the bilingual and bicultural nature of the performance well reflected in the two titles of the play, as well as the two names given to the Falklands/Malvinas Islands in the two nations that claim sovereignty over them - it seems appropriate to present here two complementary accounts, which are informed by different cultural histories, personal experiences and intellectual preoccupations. Indeed, even in formal terms, Sosa's more directly affective account of watching the work sits in 
nuanced relation to the scholarly register of Finburgh's thematic enquiry, testifying to the scope of Arias's achievement in so deftly interweaving individual, historical and political concerns. At the same time, it is telling that Sosa is ultimately drawn, as Finburgh is, to the treatment of spectacle in the work. Where Finburgh's analysis faces outward, as it were, toward the larger critique of spectacle that the performance launches, Sosa's is drawn to what she calls the 'spectacle of intimate power': something the audience is invited actively to participate in, as they navigate the gaps that must inevitably open up in such a work between history and memory, and between languages translated and untranslated.

Translation has, of course, been a key consideration in piecing together the 'Snapshot: Brazil' dossier that accompanies this issue, and nowhere have I felt that editorial stupidity discussed above more than in working with dossier editor Cláudia Tatinge Nascimento, translator Elizabeth Jackson and, through their mediation, the authors. As Tatinge Nascimento explains in her introduction, the dossier consists of two specially commissioned essays and a series of reviews. The essays reflect on the Brazilian theatre and performance landscape in light of several years of momentous social and political upheaval, which have seen turmoil over the presidency and numerous corruption scandals coincide with the hosting of two massive and costly global media spectacles: the 2014 FIFA World Cup and the 2016 Summer Olympics. Accordingly, the subject matter of Adriana Schneider Alcure's 'Art and Insurgency in Urgent Times' is unambiguous, presenting as it does a survey of activist responses to Brazil's recent troubles, and examining how artistic groups and ideas have prompted new ways of thinking about political protest. Aimar Labaki's 'Crises and Brazilian Theatre' locates the protests in relation to a longer history of political activism on the one hand, and on the other enquires more directly into the implications of recent developments on theatre aesthetics, and on how theatre-makers are innovating within their forms in order to reflect and respond to fast-changing circumstances. The collection of seven theatre reviews that follow, accompanied by a series of striking production stills, in turn fleshes out this picture by providing a snapshot not only of Brazilian theatre over the last few tumultuous years, but also of its critical culture. The reviews are as diverse in theme and style as the performances they reflect on, and working on them in collaboration with Cláudia and Elizabeth, I was reminded anew of how much theatre criticism, reflecting the majority of the performances reviewed, is oriented towards a local or national, rather than international, readership. I asked a lot of 'stupid questions' in the course of working on this dossier, and I thank both Cláudia and Elizabeth for their patience and their willingness to go far beyond the basic requirements of framing and translation in order to provide extensive explanatory notes, and to find, through dialogue, just the right words and phrases to help readers of this journal access the nuanced ways in which the authors were responding to the performances they had in mind as they wrote.

Of course, theatre itself is far from immune to stupidity. It is an art - perhaps the art-of imperfection. Assembled from the well-worn furniture of our social world, theatre expresses our collective compromise to each other, and to our situation. Sometimes, this renders theatre's utopian energies all the more compelling for their trial by actuality. At other times, and however brilliant its creators, one confronts something bovine in 
the form: something that is big, and dumb and doesn't learn, and that can leave one's mediocrity and delusions - whether as an artist or a spectator - cruelly exposed. Theatre people, in other words, know a thing or two about stupidity: they are well-placed to call it out when they see it, because they are familiar with the numbness of its touch. Working with non-knowledge, everything obscure to you about the thing you know best, is an occupational hazard of theatre scholarship. In this issue of the journal, authors have wrested a series of remarkable insights from their material. I am the less stupid for their efforts, and now they are in print, I am not the only one.

\section{NOTES}

1 Ronell Avital. Stupidity (Urbana and Chicago: University of Illinois Press, 2002), p. 24.

2 'Cowardice, cruelty, baseness and stupidity are not simply corporeal capacities or traits of character or society; they are structures of thought as such'. Gilles Deleuze, Difference and Repetition, trans. Paul Patton (London and New York: Continuum, 2004; first published 1968), p. 189.

3 Ibid.

4 Ibid. 